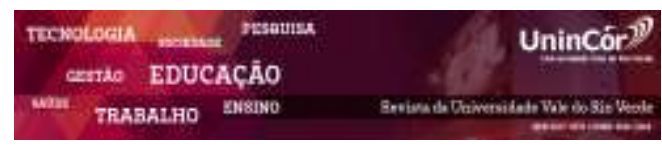

Revista da Universidade Vale do Rio Verde ISSN: 1517-0276 / EISSN: 2236-5362 Vol. 16 | n. 2 | Ano 2018

Thaís Simões Pohlmann Centro Universitário Franciscano thaispohlmann@gmail.com

Bruna Faccin Camargo

Centro Universitário Franciscano bruna.camargo@unifra.br

Jaqueline Carla Guse

Centro Universitário Franciscano jaqueline.guse@unifra.br

Lucas Almeida dos Santos Centro Universitário Franciscano lucas.santos@unifra.br

\section{ANÁLISE DO SISTEMA DE INFORMAÇÃO GERENCIAL QUANTO ADEQUAÇÃ̃O ÀS NOVAS NORMAS DE CONTABILIDADE PÚBLICA: UM ESTUDO DE CASO}

\title{
RESUMO
}

O principal objetivo desde trabalho foi realizar a verificação do sistema adotado pela Prefeitura Municipal de Santa Maria, se está adaptado as novas Normas Brasileiras de Contabilidade Aplicadas ao Setor Público. Publicado em 2008 pelo Conselho Federal de Contabilidade (CFC), as primeiras normas que passaram a ser implantadas, mas tornou-se obrigatória somente a partir de 2013. Trata-se de uma pesquisa descritiva e quantitativa, devido a coleta dos dados ter sido realizada através de aplicação de um questionário aos servidores da prefeitura no período de outubro a novembro de 2017. O resultado obtido foi que existem carências no sistema adotado por ele ainda não estar $100 \%$ adaptado as novas normas. As respostas obtidas demonstraram que falta estrutura no sistema da prefeitura, dificultando as mudanças exigidas. Exemplos de que o sistema ainda não está totalmente apto é a falta de um módulo de custos, o qual deve ser desenvolvido para atender as exigências, além disso o sistema também não emite os novos relatórios exigidos, como a Demonstração de Fluxos de Caixa (DFC) e Demonstração do Resultado Econômico.

Palavras-chave: Prefeitura Municipal de Santa Maria. Contabilidade Pública. Sistema de Informação. Normas Contabilidade Pública. NBCASP.

\section{ANALYSIS OF THE MANAGEMENT INFORMATION SYSTEM HOW FIT FOR THE NEW PUBLIC ACCOUNTING STANDARDS: A CASE STUDY}

\begin{abstract}
The main objective since work was to carry out the verification of the system adopted by the Municipal Government of Santa Maria, if the new Brazilian Accounting Standards Applied to the Public Sector were adapted. Published in 2008 by the Federal Accounting Council (CFC), the first standards to be implemented, but became mandatory only from 2013. This is a descriptive and quantitative research, because the data collection has been performed through the application of a questionnaire on the servers of the city hall from October to November of 2017. The result obtained was that there are deficiencies of the system adopted because it is not yet $100 \%$ adapted to the new standards, the answers obtained showed that there is a lack of structure in the system. prefecture, making the required changes difficult. Examples of which the system is not yet fully fit is the lack of a cost module, in which it must be developed to meet the requirements, the system also does not issue the new required
\end{abstract}


reports such as Cash Flow Statement (DFC) and Demonstration of the Economic Result.

Keywords: City Hall of Santa Maria. Public Accounting. Information system. Public Accounting Standards. NBCASP.

\section{Recebido em: 30/01/2018 - Aprovado em: 15/08/2018 - Disponibilizado em: 15/12/2018}

\section{INTRODUÇÂO}

A contabilidade pública, regulamentada pela Lei $\mathrm{n}^{\circ} 4.320 / 64$, instituiu normas para os balanços e orçamentos públicos, as quais devem ser seguidas pelos órgãos governamentais. Assim, a contabilidade pública tornou-se responsável pelo registro da previsão da receita e a fixação da despesa, pois ela demonstra a execução orçamentária da receita e da despesa, faz a comparação entre a previsão das receitas e das despesas, controla as operações de crédito, a dívida ativa, os valores, os créditos e obrigações, as variações patrimoniais e demonstra o valor do patrimônio.

Fazem parte das atribuições do contador público os atos administrativos praticados pelo administrador como contratos, convênios, acordos, ajustes, avais, fianças, comodato de bens e outros que possam afetar o patrimônio.

A partir do ano 2000, a Lei Complementar 101, chamada de Lei de Responsabilidade Fiscal (LRF) estabeleceu normas e procedimentos para o uso do dinheiro público, fixando limites de despesas, definindo regras para o cumprimento dos orçamentos, obrigando a transparência nas contas e também prevendo sanções para desvios de conduta.

Dessa forma, ao observar a Lei 4.320/64 e a Lei Complementar 101/00, pode-se afirmar que tais dispositivos devem ser considerados os principais norteadores da contabilidade pública, além dos princípios contábeis e demais legislação pertinente,

A partir do ano de 2008, iniciaram-se as mudanças nos procedimentos da contabilidade pública no Brasil, e neste sentido os órgãos competentes, uniram-se com o intuito de padronizar a contabilidade do setor público.

Nessa conjuntura, para auxiliar e orientar União, Estados e Municípios, foram criadas as Normas Brasileiras de Contabilidade Aplicadas ao Setor Público (NBCASP), que juntamente com o Manual de Contabilidade Aplicado ao Setor Público (MCASP), norteiam os procedimentos a serem praticados no país.

Com isso essas mudanças exigiram a utilização de sistemas de informação gerenciais adequados e aptos, de forma a atender as NBCASP. Atualmente, todo procedimento contábil tem como suporte o uso da tecnologia da informação uma vez que sistemas de informações gerenciais proporcionam facilidade nas informações contábeis, pois ajudam na tomada de decisões do contador, visando resultados satisfatórios.

Em se tratando do setor público, os Sistemas de Informações Gerenciais (SIG) existentes, com a adoção das citadas normas, precisam de constantes mudanças e 
implementações, fazendo com que a contabilidade possa ser evidenciada de forma eficaz.

O objetivo geral do presente trabalho foi verificar o sistema de informação gerencial adotado pela Prefeitura Municipal de Santa Maria/RS a fim de conhecer o nível e qualidade de suas informações. Seus objetivos específicos foram: verificar o sistema de informações gerenciais adotado pela Prefeitura Municipal de Santa Maria/RS com o objetivo de conhecer as informações de seus relatórios; verificar se o sistema de informações gerenciais adotado está adequado as novas normas de contabilidade aplicadas ao setor público; identificar possíveis falhas na adequação a estrutura as NBCASP.

$$
\text { Considerando que a contabilidade }
$$
pública sofreu alterações conforme já comentadas, os sistemas gerenciais contábeis também terão que se adequar às novas exigências estabelecidas pelas NBCASP, por se tratar de mudanças de comportamento e de uma nova realidade a ser enfrentada pelos contadores das entidades públicas, o assunto requer investigação quanto aos sistemas gerenciais de informações, salienta-se que os contadores são responsáveis pela operacionalidade do processo.

A seguir apresenta-se a fundamentação teórica que forneceu os dados necessários para realização desta pesquisa, a análise e apresentação dos dados obtidos através da aplicação do questionário, e as considerações finais que são partes conclusivas da pesquisa, na qual se efetua a mistura dos elementos do trabalho unindo as ideias e fechando os objetivos apresentados no trabalho.

\section{REFERENCIAL TEORICO}

Com o intuito de fundamentar conceitualmente apresente pesquisa serão apresentados alguns tópicos encontrados na literatura, quanto a normas aplicadas ao setor público e sistemas de informações gerenciais no setor público.

2.1 Normas brasileiras de contabilidade aplicada ao setor público

As NBCASP são editadas pelo Conselho Regional de Contabilidade do Rio Grande do Sul (CRCRS) e "trazem os conceitos e procedimentos patrimoniais que passam a ser exigidos na contabilidade pública municipal" (CRCRS, 2014).

Atualmente, as Normas Brasileiras de Contabilidade Aplicadas ao Setor Público são compostas por onze normativas.

Dez delas publicadas em 21 de novembro de 2008 e uma em 25 de novembro de 2011. Os principais objetivos das atuais Normas Brasileiras de Contabilidade Aplicadas ao Setor Público, segundo o Conselho Regional de Contabilidade do Rio Grande do Sul (2014), são: mensurar e evidenciar melhor o patrimônio público; utilizar conceitos científicos e não apenas legais; convergir as práticas contábeis ao padrão internacional; instrumentalizar o controle social; e prestar contas de forma mais transparente. 
2.2 Sistemas de informações gerenciais na contabilidade do setor público

O Sistema de Informação Contábil (SIC), é o instrumento que coleta, processa e transforma os dados em informações em forma de relatórios contábeis. Segundo Bagranoff, Moscove e Simkin (2002, p. 22) "os SICs são um tipo especial de sistema de informações que fornecem informações sobre processos e eventos de negócio que afetam a organização".

Ainda segundo os autores Bagranoff, Moscove e Simkin (2002, p. 24): "sistema de informações contábeis é o subsistema de informações dentro de uma organização que acumula informações de vários subsistemas da entidade e comunica-se ao subsistema de processamento de informações". O sistema de informação contábil deve produzir informações específicas na área financeira e econômica da empresa, tais como: custos, estoques, faturamento, fluxo de caixa, contas a pagar e a receber entre outras informações no que tange à contabilidade. Um software contábil bem estruturado e administrado é fundamental no controle e no processo decisório de uma organização, pois ele possibilita a emissão de relatórios em tempo oportuno e com maior segurança nas informações geradas.

Conforme Cassarro (2003, p. 26): "Já é do consenso geral, no mundo empresarial, que as informações compõem um dos maiores e mais valiosos ativos da empresa". Afirmar-se que uma empresa será mais dinâmica, mais agressiva e mais atuante do que outras na medida em que possua melhores sistemas de informações e, evidentemente, pessoal de alta e média administração, capacitado e motivado a se utilizar destas informações para as suas tomadas de decisões.

Um sistema de informação contábil quando bem administrado, tem grande utilidade no assessoramento a seus usuários de acordo com suas necessidades para que possam alcançar seus objetivos, através de informações de qualidade e em tempo hábil.

Os sistemas de informações gerenciais atuam como um instrumento administrativo, aperfeiçoando o processo decisório e a comunicação dentro das entidades, diminuindo sérios problemas que podem afetar na eficiência e efetividade, fornecendo também informações diárias através de relatórios com base nos dados e nas informações do processamento. Oliveira (2005), diz que os sistemas de informações gerenciais fazem parte do processo de transformação de dados em informações utilizadas para controle e tomadas de decisões na entidade, auxiliando na sustentação administrativa para otimizar os resultados esperados.

Segundo Camelo, Gasparello e Favero (2006), os sistemas de informações gerenciais são úteis à administração pública por possuir ferramentas que facilitam o controle e a prestação de contas à sociedade garantindo transparência das informações e mais segurança. Assim, os sistemas de informações gerenciais devem atuar de forma satisfatória no auxilio as decisões das entidades, por meio de ferramentas que facilitam na emissão de relatórios e demonstrativos que mostram a situação patrimonial da entidade. 
2.3 A importância para a gestão pública das novas normas de contabilidade aplicadas ao setor público

Ao longo dos últimos anos, a gestão pública vem agregando aprimoramento e melhorias, aperfeiçoando o planejamento de compras, da gestão orçamentária, financeira e patrimonial. A administração pública vem atuando com foco em resultados, ênfase na transparência dos seus atos e fatos, valorizando a contabilidade pública e suas demonstrações contábeis.

A partir de 2008 o governo federal e o CFC editaram as novas normas para facilitar a convergência aos padrões internacionais. Essa normatização é importante para proporcionar que o Brasil esteja ligado às padronizações impostas pela globalização.

A accountability e a transparência do setor público são umas das características das NBCASPs, as quais, a partir do princípio da competência, é possível que melhorem as informações à tomada de decisões dos gestores. $\mathrm{Na}$ percepção de Vicente (2011), as normas promoveram uma distinção entre orçamento público e a contabilidade a partir da adoção do regime de competência utilizado para os registros do patrimônio. Para os autores, as novas demonstrações contábeis ampliam a transparência fiscal dos governos, citando, por exemplo, a adoção de métodos de depreciação e a implantação de sistemas de custos, os quais contribuem para a eficiência no setor público. Outros estudos também já realizados sobre o tema abordam principalmente as alterações trazidas pelas normativas. Souza (2012) e Ciupak e Silva (2012), a partir de uma abordagem conceitual, desenvolveram seus estudos nas alterações trazidas pela adoção das NBCASPs em relação às legislações anteriores, em especial a Lei no 4.320/64, já Salaroli e Almeida (2014) analisaram o processo de elaboração das normas internacionais.

\section{METODOLOGIA}

A pesquisa é classificada quanto sua natureza em qualitativa, pois analisou o sistema utilizado na P.M.S.M. Já quanto aos objetivos a pesquisa caracterizou-se como uma pesquisa descritiva, pois se descreveu as características de determinada amostra. A pesquisa é descritiva visto que teve como objetivo verificar se o sistema utilizado pela P.M.S.M está atendendo as NBCTS. Este método foi escolhido por permitir entrevistar todos os envolvidos e assim poder retratar de forma mais objetiva a percepção dos entrevistados quanto ao tema.

Quanto aos procedimentos técnicos caracterizou-se como pesquisa de caso, uma vez que: a pesquisa de campo conforme Marconi e Lakatos (2003) está voltada para o estudo de indivíduos, grupos, comunidades, instituições, entre outros campos.

Sendo assim, a pesquisa foi realizada a partir da aplicação de questionários para um único grupo, no caso os profissionais da Secretária de Finanças de Santa Maria, portanto foi analisada a capacitação técnica dos servidores, o conhecimento e a aderência com relação às NBCASP. 


\section{RESULTADOS}

A primeira pergunta do questionário buscou saber se a P.M.S.M investiu em cursos e treinamentos para os servidores conhecerem as mudanças das NBCTS.

A maioria dos participantes afirmou que a P.M.S.M investiu em cursos e treinamentos para conhecimento das novas Normas, sendo assim conclui-se que a prefeitura investiu em treinamentos e cursos para os servidores obterem um maior conhecimento sobre as mudanças das novas normas.

A questão de número 2 indagou se o sistema adotado pela P.M.S.M está totalmente adequado aos lançamentos exigidos pelas novas Normas.

Conclui-se que o sistema adotado está parcialmente adequado aos lançamentos exigidos pelas novas Normas, pois $85,71 \%$ dos constituintes da pesquisa selecionaram esta opção, levando em consideração a obrigatoriedade das novas exigências esse resultado não é bom, pois o sistema deveria estar totalmente adaptado as novas normas desde de 2013.

O terceiro item do questionário pesquisou se o sistema adotado dispõe de relatórios de controle efetivo, quantitativo e qualitativo do seu patrimônio público. Dos entrevistados, 71,43\% responderam que o Sistema atende esse item parcialmente, que não está totalmente adequado as novas Normas, analisando os dados obtidos conclui-se que ainda existem ajustes a serem feitos até que os relatórios sejam emitidos de forma a atender totalmente as novas normas, sabendo-se que um relatório quantitativo é focado em uma análise de números já o qualitativo está mais focado a abordar aspectos mais amplos.

No quarto questionamento pesquisou-se se os subsistemas se encontram perfeitamente integrados, de forma subsidiar a administração pública com informações sobre o patrimônio público. Somente $28,57 \%$ dos entrevistados responderam que sim, os outros $71,43 \%$ respondeu que os subsistemas estão parcialmente integrados, para uma melhor administração é necessário que os subsistemas estejam totalmente integrados para uma melhor gestão e melhor visualização do patrimônio que ajudará na tomada de decisões.

$\mathrm{Na}$ quinta questão, é explorado se o sistema utilizado consegue organizar $o$ planejamento de forma a seguir as exigências do P.P.A, LDO e LOA. Conclui-se que o sistema ainda não está atendendo totalmente as novas exigências. Visto que o planejamento integrado não é matéria recente na administração pública, o mesmo foi instituído pela Lei 4.320/6, ganhando força com a Constituição Federal de 1998, que introduziu a Lei das Diretrizes Orçamentárias e ganhou respaldo com a Lei da Responsabilidade Fiscal.

A questão de número 6 , pergunta se o sistema observa aos princípios fundamentais da contabilidade e as novas Normas conforme as transações que são classificadas em econômicofinanceiro e natureza administrativa. Mais da metade dos respondentes disseram que o sistema atende parcialmente esse quesito, os outros $42,86 \%$ disseram que atende totalmente, analisase que NBCT 16.4 não está totalmente adequada 
conforme as novas normas, ainda precisa ser feito alterações

Na sétima questão indagou-se se o sistema adotado está apto a registrar todos os atos e fatos necessários com base nos Princípios Fundamentais da Contabilidade e as novas exigências das novas Normas.

A maioria dos respondentes disseram que sim, mas ainda existem ajustes a fazer para que o sistema fique totalmente apto a atender a norma. Ela estabelece que deve ser preservado procedimentos uniformes de registros contábeis, seja por meio de processo manual, mecânico ou eletrônico, apresentados em ordem cronológica.

$\mathrm{O}$ oitavo questionamento teve por sua vez verificar se a P.M.S.M sustenta um sistema refletido em um plano de contas, $100 \%$ dos questionários foram respondidos que sim, que o sistema possui um plano de contas. A NBCT 16.5 determina que as entidades do setor público devem manter sistema de informação contábil refletido em um plano de contas e o mesmo deve conter: a função das contas; o funcionamento das contas; contas especificas para a apuração dos custos; terminologia das contas e sua adequada codificação, bem como a indicação do subsistema a que pertence, a natureza e o grau de desdobramento, permitindo os registros de valores e a integração de subsistemas; tabela de codificação de registros que identifique o tipo de transação, as contas envolvidas, a movimentação a débito e a crédito e os subsistemas utilizados; a utilização dos métodos de partida dobrada em todos os registros dos atos e dos fatos que afetam ou possam vir a afetar o patrimônio das entidades. A nona questão diz que foram criadas duas demonstrações, completando as já existentes a Demonstração dos Fluxos de Caixa e a Demonstração do Resultado Econômico, o sistema adotado emite esses relatórios de forma a atender as novas Normas. O resultado apurado foi que $14,29 \%$ disse que não, que os sistemas não emitem os relatórios de forma a atender a nova norma, o restante disse que atende parcialmente. O objetivo da DFC é demonstrar as movimentações feitas nos caixas e equivalentes, separando os fluxos em operacional, de investimento e de financiamento. Para a elaboração pode ser utilizado o método direto ou o método indireto. Já o objetivo da DRE é evidenciar o resultado econômico das ações do setor público e deve conter em sua estrutura: receita econômica de serviços prestados e dos bens e ou produtos fornecidos; custos e despesas identificados com a execução da ação pública; resultado econômico apurado.

Apenas 14,29\% dos respondentes disseram que o sistema disponibiliza um módulo de controle interno, o módulo ainda não está totalmente adaptado. O controle interno sob o enfoque contábil, é representado pelo conjunto de recursos, métodos, procedimentos e processos adotados pela entidade conforme a NBCT 16.8 com o propósito de salvaguardar os ativos e assegurar a veracidade dos componentes patrimoniais; dar conformidade aos registros contábeis em relação ao ato correspondente; proporcionar a obtenção de informação oportuna e adequada; estimular a adesão as normas e as diretrizes fixadas; contribuir para promoção da eficiência operacional da entidade e auxiliar na prevenção de práticas ineficientes e antieconômicas, erros, fraudes, abusos e outras inadequações. 
Na questão 11 foi indagado se o sistema da P.M.S.M possui um eficiente controle de gestão dos bens permanentes, $100 \%$ dos respondentes disseram que o sistema possui parcialmente um eficiente controle de gestão dos bens permanentes.

$\mathrm{Na}$ décima segunda questão foi questionado se o sistema está totalmente modificado para contabilizar a depreciação/amortização/exaustão dos bens permanentes.

Quase $60 \%$ dos entrevistados, respondeu que o sistema não está totalmente modificado, $28,57 \%$ disse que atende parcialmente e o restante disse que atente totalmente. $\mathrm{O}$ sistema contábil deve incluir nos períodos em que o ativo for utilizado a apropriação gradativa de seu valor como custo ou despesa sob a denominação de amortização, depreciação e exaustão, dependendo de sua natureza.

Na penúltima questão foi indagado se o sistema tem um módulo de Custos Integrado. A maioria dos respondentes disse que o sistema não tem um módulo de custo integrado, deve ser desenvolvido um módulo de custo de maneira a tender as novas normas. Esta norma fundamentase pelo fato da ausência de critérios e definições claras sobre o método de avaliação e mensuração dos ativos e passivos que não permite a adequada evidenciação da real situação do patrimônio público.

Por fim a última questão pergunta se o sistema permite uma análise eficiente dos ativos e passivos.

Analisando as questões, observamos que o sistema ainda não está $100 \%$ adaptado as novas normas, faltando alguns ajustes de forma a atender as novas normas, em se tratando da análise do sistema de uma prefeitura, sugere-se que novas pesquisas sejam feitas em outras prefeituras da região.

\section{CONSIDERAÇÕES FINAIS}

Desde 2013, a contabilidade pública vem sofrendo mudanças e exigindo capacitação dos administradores, contadores e demais servidores para aplicação das NBCASP, da qual a ideia é originar um ambiente vantajoso à implantação das melhores práticas contábeis internacionais na Contabilidade Aplicada ao Setor Público brasileiro.

A aplicação das NBCASP vem trazendo mudanças significativas para as entidades públicas de todo país, pois o objetivo é voltado para a tomada de decisões e transparência de informações para a sociedade.

A tecnologia da informação vem atuando de forma a facilitar e proporcionar rapidez e facilidade nas informações contábeis, atribuindo aos contadores um perfil mais gerencial, visando resultados satisfatórios.

Na PMSM vem sendo feito atualizações e implementações no sistema utilizado para que ele venha a atender de forma satisfatória as novas normas frente as mudanças que vem ocorrendo ao longo dos anos.

Neste sentido a trabalho teve como objetivo verificar se o sistema adotado pela prefeitura está apto a atender as novas normas.

Avaliou-se que o sistema pesquisado é capaz de atender as novas exigências da contabilidade pública, porém, ainda necessitam 
de pequenas modificações. Principalmente quanto a implantação de um módulo de custos que contribua para melhorar a tomada de decisões, em observação a NBCT 16.11.

Esses ajustes a serem feitos não impedem aos servidores a elaboração dos procedimentos contábeis trazidos pelas NBCASP, cabendo aos mesmos a atualização continua e o comprometimento.

A frente dos resultados encontrados, com base do questionário, visando responder os objetivos desta pesquisa, conclui-se que: Em relação ao sistema utilizado pela P.M.S.M, precisa melhorar os módulos contábeis existentes que possibilitam totalmente a integração destes; e existe a carência de um sistema de custos.

Sendo assim, após 04 anos da obrigatoriedade da aplicação das novas normas, identifica-se que o sistema contábil da P.M.S.M ainda não está totalmente adaptado as novas Normas, pois na maioria das questões respondese que atende parcialmente, observando-se então que ainda faltam ajustes a serem feitos no sistema para que ele atenda totalmente as novas exigências.

Para que o sistema contábil da P.M.S.M passe a ter total condição de atender as novas Normas, atendendo suas exigências legais e mudanças é necessário que o sistema seja reformulado, principalmente para a implantação das novas demonstrações contábeis como a DFC e a DRE, um novo sistema de custos e integração total dos módulos existentes.

Respondendo então os objetivos deste trabalho, conclui-se que o sistema não está totalmente estruturado de acordo com as novas normas, ainda precisa de modificações para que os relatórios e informações sejam emitidos de maneira a atender totalmente as novas exigências, existem pequenas falhas que aos poucos estão sendo corrigidas, porém não é empecilho para que os servidores consigam efetuar seu trabalho de forma satisfatória e comprometida, buscando sempre conhecimento.

Perante as limitações deste trabalho, sugere-se para futuros estudos que se amplie o número de municípios estudados, envolvendo outras regiões do estado do Rio Grande do Sul, buscando saber se o sistema utilizado por eles já está totalmente apto a atender as novas exigências.

\section{REFERENCIAS}

ANGÉLICO, J. Contabilidade pública. 8. ed. São Paulo: Atlas, 2009.

ARAÚJO, I.; ARRUDA, D. Contabilidade pública da teoria à prática. São Paulo: Saraiva, 2007.

BAGRANOFF, N. A.; MOSCOVE, S. A.; SIMKIN, M. G. Sistemas de informações contábeis. Tradução de Geni G. Goldschmidt. São Paulo: Atlas, 2002.

BEUREN, I. M. Como elaborar trabalhos monográficos em contabilidade. 3. ed. São Paulo: Atlas, 2008.

BRASIL. Concelho Federal de Contabilidade. Resolução CFC n 1133 , de 21 de novembro de 2008. Aprova a NBC T 16.6 - Demonstrações contábeis. Diário Oficial da União, Brasília, DF, 21 nov. 2008.

Lei $\mathrm{n}^{\circ} 4.320$, de 17 de março de 1964. Estatui Normas Gerais de Direito Financeiro para elaboração e controle dos orçamentos e balanços da União, dos Estados, dos Municípios e do Distrito Federal. Diário Oficial [da] República Federativa do Brasil, Brasília, DF, 17 mar. 1964.

CAMELO, A. C. O.; GASPARELLO, E. R.; FAVERO, H. L. Sistema de informação contábil e a sua importância para o controle dos bens permanentes do setor público. Enfoque: Reflexão Contábil, v. 25, n. 1, p. 62-76, jan./abr. 2006. 
CASSARRO, A. C. Sistemas de informações para tomada de decisões. 3. ed. São Paulo: Pioneira, 2003.

CRCRS. Conselho Regional de Contabilidade do Rio Grande do Sul. Normas Brasileiras de Contabilidade Aplicadas ao Setor Público sob a ótica das IPSAS: um estudo comparativo. 2. ed. Porto Alegre: Conselho Regional de Contabilidade do Rio Grande do Sul, 2014.

GIL, A. C. Métodos e técnicas de pesquisa social. 5. ed. São Paulo: Atlas, 1999.

Como elaborar projetos de pesquisa. 4. ed. São Paulo: Atlas, 2002.

Como elaborar projetos de pesquisa. 5. ed. São Paulo: Atlas, 2010.

KOHAMA, H. Contabilidade pública teoria e prática. 12. ed. São Paulo: Atlas, 2012.

Contabilidade pública teoria e prática. 14. ed. São Paulo: Atlas, 2014.

MARCONI, M. de A.; LAKATOS, E. M.

Fundamentos de metodologia científica. 5. ed. São Paulo: Atlas, 2003.

Metodologia científica. 5. ed. São Paulo: Atlas, 2007.

OLIVEIRA, D. de P. R. de. Sistemas de informações gerenciais. 10. ed. São Paulo: Atlas, 2005.

PISCITELLI, R. B.; TIMBÓ, M. Z. F. Contabilidade Pública - Uma abordagem da administração financeira pública. 12. ed. rev., ampl. e atual. São Paulo: Atlas, 2012.

PREFEITURA DE SANTA MARIA. Organograma da Secretaria de Município de Finanças. 2017.

Disponível em:

<http://www.santamaria.rs.gov.br/financas/138secretaria-de-municipio-de-financas $>$. Acesso em: 10 nov. 2017.

REZENDE, D. A. Sistemas de Informações Organizacionais - Guia Prático para projetos em cursos de administração, contabilidade e informática. São Paulo: Atlas, 2005.
RIBEIRO, J. F. Ensino da contabilidade aplicada ao setor público: mudanças. In: ENCONTRO NACIONAL DE COORDENADORES DO CURSO DE CIÊNCIAS CONTÁBEIS, 4., 2009, Brasília. Anais... Brasília: Concelho Federal de Contabilidade, 2009.

RICHARDSON, R. J. et al. Pesquisa social: métodos e técnicas. São Paulo: Atlas, 1999.

\section{RODRIGUES, W. C. Metodologia Científica.}

Paracambi: FAETEC/IST, 2007.

SILVA, A. C. R. da. Metodologia da pesquisa aplicada à Contabilidade. São Paulo: Atlas, 2003.

SILVA, L. M. Contabilidade Governamental: um enfoque administrativo da nova contabilidade pública. 8. ed. São Paulo: Atlas, 2009.

SILVA, E. L., MENEZES, E. M. Metodologia da pesquisa e elaboração de dissertação. 4 . ed. rev. e atual. Florianópolis: UFSC, 2000.

\section{Thaís Simões Pohlmann}

Bacharel em Ciências Contábeis - Centro Universitário Franciscano

\begin{tabular}{l}
\hline Bruna Faccin Camargo \\
Contadora e Doutoranda em Contabilidade e \\
Finanças (UNIZAR). Docente no Centro \\
Universitário Franciscano.
\end{tabular}

Jaqueline Carla Guse

Mestre em Ciências Contábeis (FURB). Docente no Centro Universitário Franciscano.

Lucas Almeida dos Santos

Doutorando em Administração (UFSM). Docente no Centro Universitário Franciscano. 